\title{
ALLGEMEINE BESTIMMUNGEN
}

Die Sammlung des Kgl. Kunstgewerbe-Museums ist unentgeltlich geöffnet:

An den Wochentagen mit Ausnahme des Montags:
April bis September
IO-4 Uhr
Oktober bis März
IO-3 Uhr.
Sonntags:
April bis September
12--6 Uhr
Oktober und März
t2-5 Uhr
November und Februar 12-4 Uhr
Dezember und Januar I $2-3$ Uhr.

Geschlossen ist die Sammlung an allen Montagen, ferner am Neujahrstag, am Charfreitag, am Bufstag, am Himmelfahrtstag und an den ersten Feiertagen der hohen Feste; an deren zweiten Feiertagen ist sie wie an den Sonntagen der betreffenden Monate geöffnet.

Das Zeichnen nach den ausgestellten älteren Stücken ist ohne weitere Anfrage gestattet. Für moderne und \%eitweilig ausgestellte Stücke bedarf es der schriftlichen Erlaubnis des Besitzers. Abformungen behufs mechanischer Vervielfaltigung werden nicht gestattet.

Kleinere Gegenstände können zu eingehendem Studium zeitweilig in das Kopierzimmer gebracht werden. Für diese und andere besondere Vergünstigungen bedarf es der Erlaubnis des Direktors der Sammlung.

Schirme und Stöcke sind in der Garderobe abzugeben. Den Aufsehern ist die Annahme von Geschenken untersagt.

Bibliothek und Ornamentstich-Sammlung. Besondere Bestimmungen am Schlufs: Seite 152 .

Unterrichts-Anstalt. Die Lehrpläne und sonstigen Nachweise sind in der Kan\%lei der Unterrichts-Anstalt zu haben.

Königliches Kunstgewerbe-Museum

Berlin SW. 12, Prinz Albrecht-Strafse 7. 